\title{
Potential of autogenous or fresh-frozen allogeneic bone block grafts for bone remodelling: a histological, histometrical, and immunohistochemical analysis in rabbits
}

\author{
E.A. Garbin Junior ${ }^{a}$, V.N. de Lima ${ }^{\text {a,* }}$, G.A.C. Momesso ${ }^{a}$, J.M. Mello-Neto ${ }^{a}$, N.M. Érnica ${ }^{b}$, \\ O. Magro Filho ${ }^{\mathrm{a}}$ \\ ${ }^{a}$ UNESP_Univ Estadual Paulista, Araçatuba Dental School, Surgery and Integrated Clinic Department, Araçatuba, SP, Brazil \\ ${ }^{\mathrm{b}}$ School of Dentistry, West Parana State University_UNIOESTE, Cascavel, PR, Brazil
}

Available online 9 April 2017

\begin{abstract}
Our aim was to compare the wound healing of autogenous bone grafts with that of fresh-frozen allogeneic block bone in rabbits. We used 25 animals. One was killed before the experiment to provide the allogeneic bone, and the remainder were killed at four time points $(n=6$ in each group). On histometrical analysis there was a significant difference between the two groups only at 45 days and between 15 and 45 days in the intergroup analysis. However, there was significantly more revascularisation $(\mathrm{p}<0.05)$, resorption $(\mathrm{p}<0.05)$, and bony replacement $(\mathrm{p}<0.05)$ in the autogenous group in the immunohistochemical analysis. In later periods, the autogenous bone was replaced by newly-formed bone in all samples, whereas it was always possible to find regions of devitalised bone in the fresh-frozen allogeneic bone grafts. Autogenous grafts were completely replaced whereas, in the fresh- frozen allogeneic grafts, we found acellular tissue that had been incorporated into the receptor bed interface during the later evaluation times.
\end{abstract}

(C) 2017 The British Association of Oral and Maxillofacial Surgeons. Published by Elsevier Ltd. All rights reserved.

Keywords: Bone Bank; Implants; Bone Graft; Bone Remodelling; Tissue Scaffold

\section{Introduction}

The advantages of using tissue banks for reconstruction of alveolar bone include reductions in anaesthetic and operating times, as well as in postoperative morbidity. No intervention is required in a donor area, and the surgeon is able to reconstruct large areas using only local anaesthesia. ${ }^{1,2}$

We know of no standardisation or consensus of information about the techniques used to treat bony tissue until it is frozen. ${ }^{3,4}$ Other issues are the effect of freezing on bone repair and the behaviour of tissue over time; these cause surgeons to wonder about its applicability in implant dentistry. ${ }^{5-8}$

\footnotetext{
* Corresponding author at: St. Jose Bonifacio, 1193, 16015-050 Aracatuba, SP, Brazil. Tel./fax: +55 $4536363270 ;+5585999250201$.

E-mail address: valthierre@gmail.com (V.N. de Lima).
}

This study is justified by the need for further details about the dynamics of freezing allogeneic bone, because most previous reports have studied only the use of frozen allogeneic bone. ${ }^{9,10}$

\section{Aim of the study}

Our aim was to evaluate the process of healing of autogenous bone grafts and fresh-frozen allogeneic block bone repairs in rabbit mandibles using histological, histometrical, and immunohistochemical analyses. The findings will later be incorporated into rehabilitation with dental implants.

Our null hypothesis was that the allogeneic block bone would be incorporated into the receptor bed in a similar way to that of the autografted block bone. 


\section{Material and methods}

We studied 25 white, adult male (New Zealand) albino rabbits that were six months old and weighed 3 to $4 \mathrm{~kg}$ from the central vivarium of Araçatuba Dental School - UNESP. This research was approved by the Ethics Committee for Animal Experimentation (83/05).

One of the animals was killed at the beginning of the study to obtain allogeneic bone; its right metaphyseal tibia was removed, packed, and sent to the tissue bank in accordance with instructions. At the tissue bank the bone went through a pre-established decontamination process, after which it was packed and frozen at $-70{ }^{\circ} \mathrm{C}$.

The remaining animals were fasted preoperatively for eight hours before being weighed and sedated with ketamine $50 \mathrm{mg} / \mathrm{kg}$ and xylazine hydrochloride $5 \mathrm{mg} / \mathrm{kg}$ intramuscularly. The regions of the mandibular angle and right tibia were then shaved and disinfected bilaterally. Each animal was simultaneously used in two groups - the left mandible was the autogenous graft group, and the right mandible the frozen allogeneic bone group.

\section{Autogenous graft group}

After local anaesthesia with $2 \%$ mepivacaine hydrochloride and 1:100 000 epinephrine, the internal superior face of the right tibia was exposed by incision and separation until bony tissue was exposed close to the tibiofemoral joint. A cortical block of bone tissue was removed with a trephine burr $8 \mathrm{~mm}$ in diameter mounted in a straight hand piece and powered by an electric motor. This was kept immersed in $0.9 \%$ physiological saline until it was fixed in the receptor bed.

A skin incision was then made in the region of the left mandibular angle. Bone was exposed and separated, and the receptor bed prepared with slight decortication using a spherical diamond burr $\mathrm{N}^{\circ} 6$. The autogenous bone block was then fixed in the receptor bed with a $1.5 \mathrm{~mm} \times 8 \mathrm{~mm}$ titanium screw. The soft tissue was closed in layers with a 5/0 nylon suture.

\section{Frozen allogeneic bone group}

An $8 \mathrm{~mm}$ trephine burr was used to remove a disc of the frozen tibia, which was kept in sterile physiological saline $(0.9 \%)$ until it was fixed to the receptor bed in the right mandibular angle, using the same technique as described in the autogenous group.

During the postoperative period the animals received $0.2 \mathrm{ml}$ of veterinary pentabiotic (Fort Dodge, Campinas, SP, Brazil) intramuscularly, one dose during the immediate postoperative period and the other five days later, together with three doses of sodium dipyrone (Novalgina - São Paulo, Brazil) $1 \mathrm{mg} / \mathrm{kg} / \mathrm{day}$. Animals were killed in groups of six $15,45,120$, and 180 days postoperatively.

\section{Laboratory processing}

The mandibles were dissected, and a bone sample including the entire graft was sent to the laboratory where the bone was fixed and decalcified, the screws were removed, and samples were embedded in paraffin. The serial cuts were obtained by placing the graft in its longitudinal direction in relation to the screw to see the graft in its receptor bed.

Slides were stained with haematoxylin and eosin for qualitative histological and histometrical evaluation by light microscopy.

Histometrical analysis: photomicrographs were imported to the ImageJ analysis program (Processing Software and Image Analysis, Ontario, ON, Canada) and the "freehands" option was selected to measure the amount of new bone $\left(\mu \mathrm{m}^{2}\right)$ that had formed at the graft/bed interface for all groups and periods.

Immunohistochemical analysis: for immunohistochemical processing, osteocalcin protein (OC, goat antioc, Santa Cruz Biotechnology ${ }^{\circledR}$, USA), tartrate-resistant acid phosphatase lysosomal enzyme (TRAP, goat antitrap, Santa Cruz Biotechnology ${ }^{\circledR}$ ), vascular endothelial growth factor (VEGF, goat antivegf, Santa Cruz Biotechnology ${ }^{\circledR}$ ), and platelet endothelial cell adhesion molecule (PECAM-1, goat antipecam- Santa Cruz Biotechnology $\left.{ }^{\circledR}\right)$ were used as primary antibodies. The biotinylated secondary antibody was donkey antigoat (Jackson Immunoresearch Laboratories, West Grove, USA). The reaction signal was amplified with the streptavidin-biotin system (DAKO Kit, DAKO Co, USA), and the reaction exposed using diaminobenzidine (DAB, DAKO Co) as the chromogen. Immunohistochemical controls were used to evaluate the effectiveness and specificity of the reactions.

The pattern of expression of each protein was analysed for each group after periods of 15,45 , and 120 days. The first period was considered as the initial analysis, the second as the intermediate analysis, and the third as the late analysis, in an attempt to involve the entire extent of the blocks. The expression of proteins was evaluated using the following scores: absent (score 0 ), positive (score 1), superpositive (score 2), and hyperpositive (score 3). ${ }^{11}$

\section{Statistical analysis}

A normality test (Shapiro-Wilk) was applied to the data obtained from the histometrical analysis, which showed a normal distribution (Sigmaplot 12.3 software; Systat Software Inc, San Jose, CA, USA). We then used a two-way analysis of variance (ANOVA) and Tukey post-hoc test to compare the grafts used (autogenous and allogeneic) and the periods analysed $(15,45,120$, and 180 days $)(\mathrm{p}<0.05)$.

For immunohistochemical analysis, we applied a normality test (Shapiro-Wilk), which showed normally distributed results for all proteins. A two-way ANOVA and Tukey posthoc test were used for data that showed significant differences 
$(\mathrm{p}<0.05)$. The power test showed that we needed five animals/group and time period to obtain an $\alpha$ of $95 \%$ and power of 0.88 .

\section{Results}

\section{Descriptive histological analysis}

In the autogenous group at 15 days we could see new bone between the receptor bed and the bone graft, and revascularisation inside the nutrition canals. In the allogeneic group there were a few areas with revascularisation in the nutrition canals and some non-vital bone.

At 45 and 120 days, the autogenous group had intense vascularisation and osteogenic activity near the bone graft and new bony tissue. The new bone was well-vascularised and uniform, and occupied the entire extent of the graft. In the allogeneic group there was discrete vascularisation and osteogenic activity, and a large quantity of non-vital bone together with areas of bone without replacement.

At 180 days, grafted bone tissue in the autogenous group could be characterised as mature bone (Fig. 1). In the allogeneic group there were regions of empty osteocytic lacunae along the extension of the block (Fig. 2).

\section{Histometrical analysis}

Large areas of new bone were present at 120 and 180 days in both groups, and in the autogenous group $98 \%$ and $99 \%$ of the surface areas were covered at 120 and 180 days, respectively. In the allogeneic group $96 \%$ and $98 \%$ were covered ( $\mathrm{p}=0.45$ and 0.711 , respectively). When results in the autogenous graft group were analysed individually, the results at 15 and 45 days showed smaller areas of new bone than those at 120 and 180 days ( $42 \%$ and $47 \%$, respectively), and there were significant differences among all periods analysed, except at 120 and 180 days $(\mathrm{p}<0.001)$.

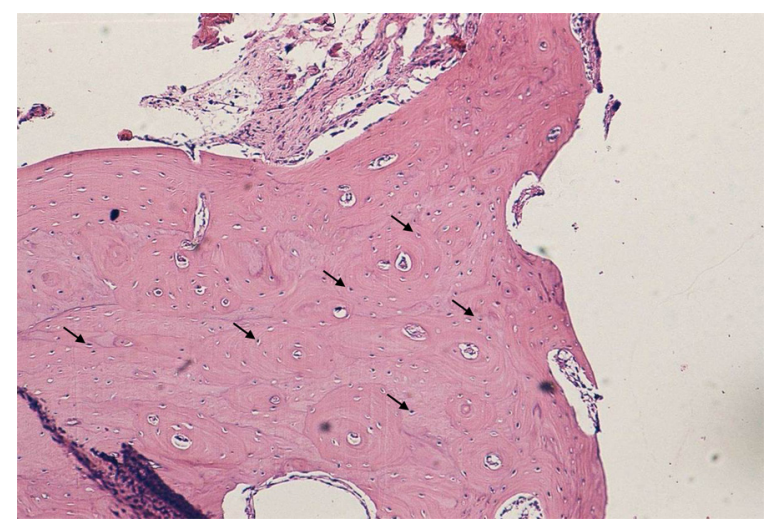

Fig. 1. Histological slide from the autogenous graft group at 180 days (haematoxylin and eosin, original magnification x 63). Note that the bony tissue next to the fixation screw (S) has been completely remodelled and revascularised, and the cells are viable.

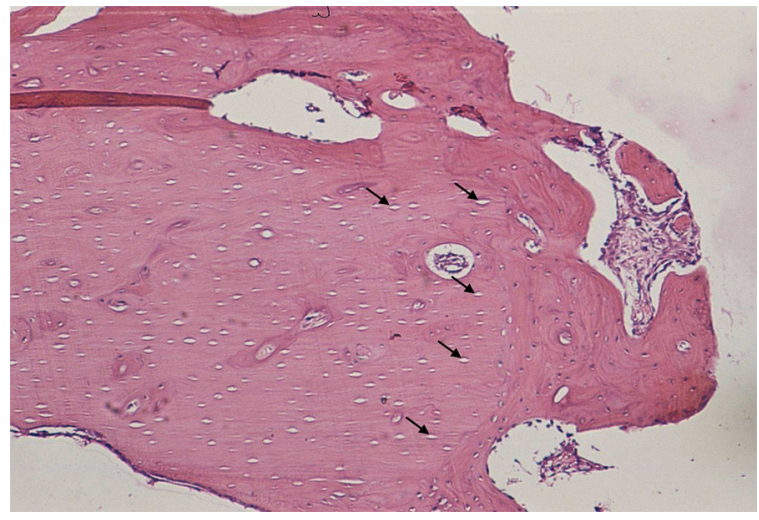

Fig. 2. Histological slide from the frozen allogeneic bone group at 180 days (haematoxylin and eosin, original magnification x 63). The frozen allogeneic bone grafts showed extensive regions of non-viable osteocytes (arrows).

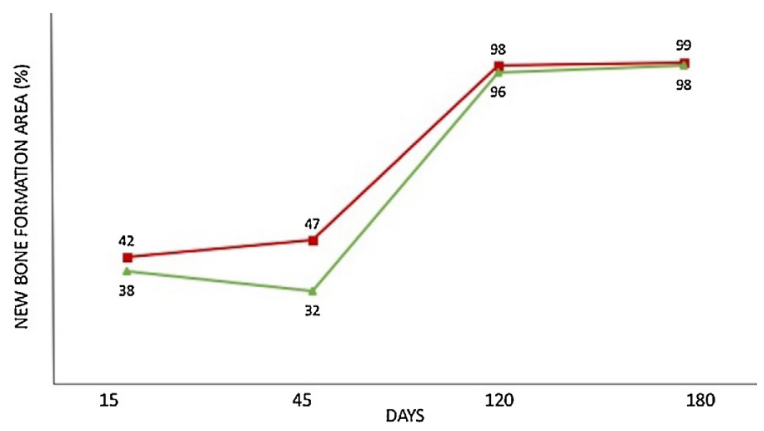

Fig. 3. Histometrical results showing the percentage of newly-formed bone in all groups at each time period. The red line indicates the autogenous bone, and the green line the allogeneic bone.

Table 1

Representative immunolabelling scores of osteocalcin (OCN), tartrateresistant acid phosphatase lysosomal enzyme (TRAP), vascular endothelial growth factor (VEGF), and platelet endothelial cell adhesion molecule (PECAM 1).

\begin{tabular}{lllll}
\hline Groups (days) & OCN & TRAP & VEGF & PECAM-1 \\
\hline Autogenous: & & & & \\
15 & 2 & 2 & 3 & 3 \\
45 & 3 & 3 & 2 & 2 \\
120 & 3 & 3 & 2 & 2 \\
Allogeneic: & & & & \\
15 & 1 & 1 & 1 & 1 \\
45 & 1 & 1 & 1 & 1 \\
120 & 1 & 1 & 1 & 1 \\
\hline
\end{tabular}

When the areas of new bone in each group were compared, there was a significant difference only at 45 days $(\mathrm{p}<0.001)$, when it covered $47 \%$ of surface area in the autogenous group and $32 \%$ in the allogeneic group (Fig. 3).

\section{Immunohistochemical analysis}

The scores are shown in Table 1. The slices in Figs. $4 \mathrm{a}$ and $4 \mathrm{~b}$ indicate the immunolabelling of VEGF at 15 days for each group. 


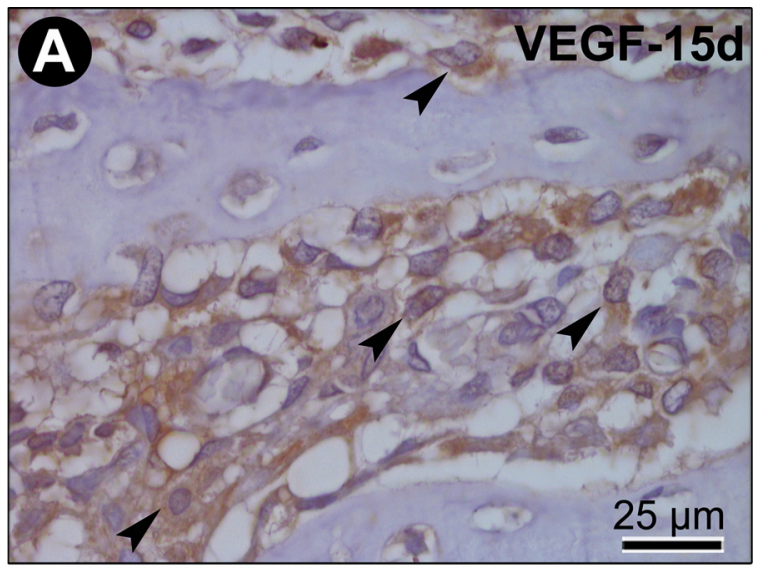

Fig. 4a. Immunohistochemical slide from the autogenous graft group at 15 days (original magnification $\mathrm{x} 63$ ) showing superpositive marking for VEGF (arrows).

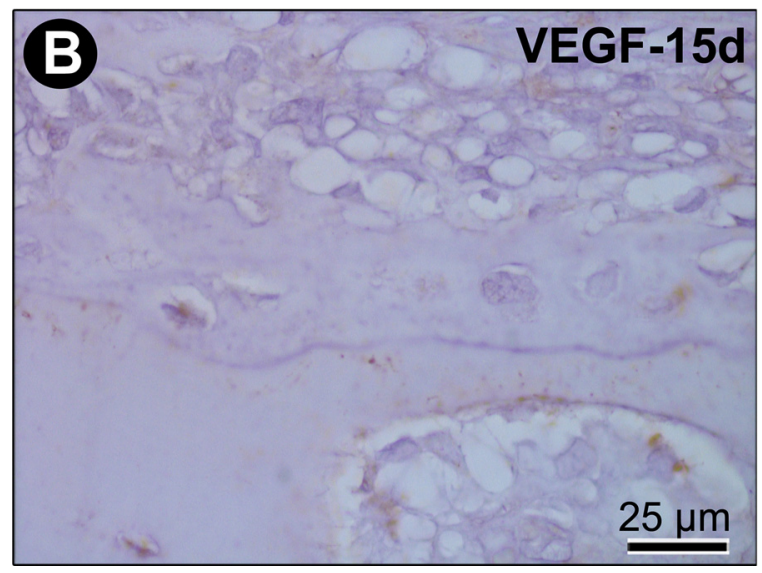

Fig. 4b. Immunohistochemical slide from the frozen allogeneic bone group at 15 days (original magnification $\mathrm{x} 63$ ) showing marking for VEGF (arrow) that was hardly positive.

Osteocalcin: there was a more expressive presentation of markers in the autogenous group (scores 2-3) compared with the allogeneic group (score 1).

Tartrate-resistant acid phosphatase lysosomal enzyme (TRAP): at 45 days there was greater resorptive activity in the autogenous group (scores 2-3) than in the allogeneic group (score 1).

Vascular endothelial growth factor (VEGF): there was more expressive presentation of markers in the autogenous group at all periods $(15,45$, and 120 days) (scores $2-3)$ than in the allogeneic group (score 1), which indicated more newlyformed blood vessels.

Platelet endothelial cell adhesion molecule (PECAM-1): there was more labelling in the autogenous group at all periods (scores 2-3) than in the allogeneic group (score 1).

All comparisons of immunolabelling of protein and periods of analysis showed differences between groups and time periods $(\mathrm{p}<0.001)$. The autogenous group had significantly more labelling of proteins than the allogeneic group, regardless of the time period $(\mathrm{p}<0.05)$.

\section{Discussion}

At 45 days the autogenous graft was superior in terms of formation of new bone, because it provided osteogenic cells and had osteoinductive properties. This resulted in more osteogenesis at the site of the interface bed and graft than seen with the allogeneic graft. During this period in rabbits bone heals through the intermediate phase of bony deposition, and the maturation phase is beginning at the same time. ${ }^{12}$

During the last time periods (120 and 180 days), both the autogenous and allogeneic grafts showed a similar amount of bony formation at the interface bed/donor sites. These results were confirmed by histological analysis, when the interface bed/graft sites were filled with mature bone. However, it was clear that in the allogeneic group the bony tissue was harvested without osteocytes, and there were no cells lining the Haversian canals, so there was no sign of incorporation of the allogeneic graft with the bed, and only the line of the interface was apparent.

The quantities of newly-formed blood vessels that penetrated the inferior surface of the autogenous graft block in the midst of the nutrition canals and the beginning of osteogenic activity (that were visible during the initial period of evaluation) are similar to those described elsewhere, where it is mentioned that pre-existing vascular canals are penetrated by blood vessels and resorptive cells that allow revascularisation of the tissue and later bony replacement. ${ }^{13,14}$ The immunohistochemical results of VEGF and PECAM-1 were also corroborated by the findings in these studies. ${ }^{2,12,15}$

This was not as apparent in the frozen allogeneic group, which confirmed that the repair was already deficient and slow during the initial stage of revascularisation and tended to persist longer. ${ }^{16}$ It is thought that failures or even deficiencies in the repair process in frozen allogeneic bone could be attributed to the delay or compromise of the initial revascularisation process, which could be immunologically mediated. ${ }^{17}$

The differences in expression by positive immunomarking obtained for TRAP and OC that were verified in the autogenous group at 15,45 , and 120 days confirm the superiority of the dynamics of the repair process in this type of graft, as they show that there is more resorption and deposition of minerals through cellular expression.

The extensive initial loss of vitality from bone in both groups, indicated by empty osteocytic lacunae, coincides with observations in studies that used autogenous bone grafts (even with a covering of periosteal tissue) and kept alive only the peripheral cells, which have a strong osteogenic function. ${ }^{18,19}$

Supporters of the use of fresh-frozen allogeneic bone argue that the preserved bony mineral structure of the grafts would be filled with new osteocytes from the receptor bed after osteointegration. They postulate that the loss of cell viability seen after cryopreservation, therefore, does not contraindicate its use, because the grafts do not depend on live cells to regenerate themselves but on the bony matrix, in 
which the morphogenetic proteins that are directly responsible for osteoinduction are found. ${ }^{20}$

We found that the frozen allogeneic group still showed areas of necrotic tissue even as late as 180 days, possibly because of the delay in the initial process of revascularisation. We did not find this in the autogenous group, which was completely revascularised by 180 days with viable cells and an established remodelling process. This corroborates studies that have shown that a fresh-frozen allogeneic graft may never be completely remodelled, and that remaining areas of non-vital tissue are maintained even for long periods after grafting. ${ }^{9,10}$

Despite the lack of revascularisation, a graft can remain structurally unaltered for an indefinite period because the cells responsible for resorption do not have access to the graft. Neither resorption nor osteogenesis is therefore possible without the bone being revascularised. ${ }^{14}$

The areas of necrotic, non-vascularised tissue in the allogeneic bone implants could create conditions for the formation of areas of bony sequestration later, and could generate exposure of bone on the ridge after a long period of time after grafting, a fact that could make complete removal of the bone block necessary. The short-term evaluation could lead to a mistaken impression of success, as observed by Pereira et al. ${ }^{21}$

However, when this is evaluated in the long term, the success rate is compromised. Deluiz et $\mathrm{al}^{22}$ reported 58 freshfrozen bone allografts in maxillary alveolar augmentation, and $22 \%$ of cases had some complication at the receptor site (10\% infection, $9 \%$ dehiscence, $12 \%$ mucosal perforation, and $7 \%$ partial and $5 \%$ total loss of the graft) at the 12-month follow-up.

Autogenous graft replacement was complete, therefore, whereas in the allogeneic group (even at the later time points of evaluation) we could still see both unremodelled tissue and acellular tissue incorporated into the receptor/bed interface.

\section{Conflict of interest}

We have no conflicts of interest.

\section{Ethics statement/confirmation of patients' permission}

This research was approved by the Ethics Committee for Animal Experimentation (83/05) at the Dental School. Patients' permission not applicable.

\section{References}

1. Pinholt EM, Haanaes HR, Donath K, et al. Titanium implant insertion into dog alveolar ridges augmented by allogenic material. Clin Oral Implants Res 1994;5:213-9.
2. Lumetti S, Galli C, Manfredi E, et al. Correlation between density and resorption of fresh-frozen and autogenous bone grafts. Biomed Res Int 2014;2014:508328.

3. McAllister DR, Joyce MJ, Mann BJ, et al. Allograft update: the current status of tissue regulation, procurement, processing, and sterilization. Am J Sports Med 2007;35:2148-58.

4. Buck BE, Malinin TI. Human bone and tissue allografts. Preparation and safety. Clin Orthop Relat Res 1994;303:8-17.

5. Ellis III E, Sinn DP. Use of homologous bone in maxillofacial surgery. $J$ Oral Maxillofac Surg 1993;51:1181-93.

6. Becker W, Becker BE, Caffesse R. A comparison of demineralized freezedried bone and autologous bone to induce bone formation in human extraction sockets. J Periodontol 1994;65:1128-33. Erratum: J Periodontol 1995; 66:309.

7. Petrungaro PS, Amar S. Localized ridge augmentation with allogenic block grafts prior to implant placement: case reports and histologic evaluations. Implant Dent 2005;14:139-48.

8. Piattelli A, Scarano A, Piattelli M. Microscopic and histochemical evaluation of demineralized freeze-dried bone allograft in association with implant placement: a case report. Int J Periodontics Restorative Dent 1998; 18:355-61.

9. Ullmark G, Obrant KJ. Histology of impacted bone-graft incorporation. J Arthroplasty 2002;17:150-7.

10. Pimentel AC, Napimoga MH, Manzi MR, et al. Reconstruction of the edentulous mandible with fresh frozen bone grafts and implants: a 4year report of a prospective clinical study. Cell Tissue Bank 2014;15: $1-6$.

11. Ramalho-Ferreira G, Faverani LP, Momesso GA, et al. Effect of antiresorptive drugs in the alveolar bone healing. A histometric and immunohistochemical study in ovariectomized rats. Clin Oral Investig 2016:1-10.

12. Queiroz TP, Hochuli-Vieira E, Gabrielli MA, et al. Use of bovine bone graft and bone membrane in defects surgically created in the cranial vault of rabbits. Histologic comparative analysis. Int J Oral Maxillofac Implants 2006;21:29-35.

13. Marx RE, Garg AK. Bone structure, metabolism, and physiology: its impact on dental implantology. Implant Dent 1998;7:267-76.

14. Rogers GF, Greene AK. Autogenous bone graft: basic science and clinical implications. J Craniofac Surg 2012;23:323-7.

15. Spin-Neto R, Landazuri Del Barrio RA, Pereira LA, et al. Clinical similarities and histological diversity comparing fresh frozen onlay bone blocks allografts and autografts in human maxillary reconstruction. Clin Implant Dent Relat Res 2013;15:490-7.

16. Davy DT. Biomechanical issues in bone transplantation. Orthop Clin N Am 1999;30:553-63.

17. Mizutani A, Fujita T, Watanabe S, et al. Experiments on antigenicity and osteogenicity in allotransplanted cancellous bone. Int Orthop 1990; 14:243-8.

18. Cypher TJ, Grossman JP. Biological principles of bone graft healing. $J$ Foot Ankle Surg 1996;35:413-7.

19. Contar CM, Sarot JR, da Costa MB, et al. Fresh-frozen bone allografts in maxillary ridge augmentation: histologic analysis. J Oral Implantol 2011;37:223-31.

20. Spin-Neto R, Stavropoulos A, Coletti FL, et al. Graft incorporation and implant osseointegration following the use of autologous and fresh-frozen allogeneic block bone grafts for lateral ridge augmentation. Clin Oral Implants Res 2014;25:226-33.

21. Pereira E, Messias A, Dias R, et al. Horizontal resorption of fresh-frozen corticocancellous bone blocks in the reconstruction of the atrophic maxilla at 5 months. Clin Implant Dent Relat Res 2015;17(suppl 2):e444-58.

22. Deluiz D, Oliveira L, Fletcher P, et al. Fresh-frozen bone allografts in maxillary alveolar augmentation: analysis of the complications, adverse outcomes and implant survival. J Periodontol 2016;87:1261-7. 